\title{
DON ALVARO TARFE: EL PERSONAJE MORISCO DE AVELLANEDA Y SU VARIANTE CERVANTINA
}

\author{
M. ${ }^{a}$ Soledad Carrasco Urgoiti. \\ Hunter College of C. U. N. Y.
}

\begin{abstract}
El nombre "don Alvaro Tarfe" evoca una figura dual que componen dos personajes literarios, el de Avellaneda y el de Cervantes. No se pretende en este trabajo analizar cómo se configura cada uno de ellos visto como construcción verbal ${ }^{1}$. Aunque todo personaje esté exclusivamente formado, como se lee en el ya clásico tratado de René Wellek y Austin Warren, por "las frases que lo retratan o que el autor pone en su boca" ${ }^{2}$, el lector establece asociaciones con su mundo propio, guiado por los signos que introduce el autor, entre los cuales el primero suele ser el nombre. La reflexión que sigue se centra en el valor referencial de los personajes, y tiene en cuenta el tratamiento que en otras obras de ficción recibe el sector social que representan, así como el juego dialéctico que relaciona entre sí los libros a que pertenecen. Al comparar las dos variantes de la misma figura, hay que advertir que la conexión entre ambas surge a la inversa del proceso que en términos generales vincula el apócrifo Segundo tomo del ingenioso hidalgo don Quixote de la Mancha, aparecido en 1614 bajo el seudónimo de Alonso Fernández
\end{abstract}

\footnotetext{
1 "The novelist, unlike many of his colleagues, makes up a number of word-masses roughly describing himself (roughly: niceties shall come later), gives them names and sex, assigns them plausible gestures, and causes them to speak [...]." (E. M. Forster, Aspects ef the Novel, New York, 1927, págs. 70-71). Ricardo Gullón expresa el mismo concepto, pero afiadiendo un matiz que nos interesa: "Texto, conflicto y personaje son construcciones verbales, y por lo mismo que son vehículos de comunicación transportan emociones e ideas" (Psicologías del autor y lógicas del personaje, Madrid, Taurus, 1979, pág. 31). Recoge opiniones de novelistas y críticos sobre la materia Rafael Azuar Carmen, Teoria del personaje literario y otros estudios sobre la novela, Alicante, Instituto de Estudios Juan Gil-Albert, 1987.

2 Teoría literaria, Madrid, Gredos, 1953, pág. 36.
} 
de Avellaneda ${ }^{3}$, a la auténtica Segunda parte del ingenioso cavallero Don Quixote de la Mancha, publicada al año siguiente ${ }^{4}$. En este caso el autor de la continuación espúrea no imita un personaje de la primera parte, sino que crea el que en cierto sentido adoptará Cervantes 5 .

Trataré primero del hidalgo granadino don Alvaro Tarfe, presentado en la continuación apócrifa, aunque en nuestra época nos familiarizamos con las dos caras de esta figura dual en orden inverso al de las fechas de composición de los libros a que pertenecen. Sólo en $1614 \multimap$ quizás durante el siglo xviri, cuando la adaptación de Lesage prestigió la obra de Avellaneda-, es verosimil que alguien leyera la continuación espúrea antes que la Segunda parte del Quijote cervantino. Y ello no deja de crear dificultades, si queremos reconstruir la imagen que el personaje que comentamos proyectaba -0 se pretendía que proyectase en la experiencia de la lectura- cuando se publicó el libro de que forma parte. La circunstancia de que el personaje cervantino del mismo nombre se haya instalado en nuestra mente mucho antes de que leyéramos el Quijote apócrifo, puede explicar la escasa atención que se ha prestado al valor referencial del primer don Alvaro Tarfe como cristiano nuevo de origen moro. Este es un aspecto que hemos de examinar, teniendo en cuenta las posiciones sustentadas por Avellaneda y los criterios literarios que se han podido deducir de su práctica. Terminaremos observando cómo, entre otras réplicas, Cervantes se desquitó del secuestro de don Quijote y Sancho al apropiarse de la figura del hidalgo granadino y perfilarla a su gusto, para que cumpliese el papel de testigo que da fe del abismo que separa la pareja cervantina de su copia.

La crítica está de acuerdo en que el autor que se oculta bajo el seudónimo de Alonso Fernández de Avellaneda, estructura su libro sobre las líneas maestras que habian quedado sentadas en el Quijote de 1605, pero el autor no asume las matizaciones que Cervantes introdujo en la caracterización de los personajes y la condena de los libros de caballerías. Stephen Gilman sostuvo, a mi juicio con todo fundamento, que esta diferencia no se debe a una total ceguera ante la complejidad de la obra y lo ambiguo de los juicios que en ella se emiten, sino más bien a un rechazo consciente de cuánto tiene el

3 Utilizo la siguiente edición: Alonso Fernández de Avellaneda, Don Quijote de la Mancha. Edición, introducción y notas de Martín de Riquer, Madrid, Espasa-Calpe, 1972 (Clásicos Castellanos, 174-176). Las referencias incluidas entre paréntesis en el texto del presente estudio remiten a esta edición, indicando capítulo, volumen y paginación.

- En este trabajo remito a Miguel de Cervantes, El ingenioso hidalgo Don Quijote de la Mancha, edición, introducción y notas de Luis Andrés Murillo, Madrid, Castalia, 1978 , vols. I-II.

- Desde una perspectiva distinta a la nuestra, analiza la figura estudiada Elizabeth Wilhelmsen, "Don Âlvaro Tarfe: ¿ente fantasmal o hecho ficticio?", ACerv, XXVIII, 1990, págs. 73-85. 
Quijote de reflexión crítica sobre instituciones y principios de autoridad ${ }^{6}$. Lo que Avellaneda acepta e imita es un esquema generador de la peripecia en que el resorte de la acción es una perturbación mental del protagonista causada por la prolongada inmersión de su espiritu, a través de la lectura, en un mundo imaginario donde se imponen la virtud y la fuerza de un individuo excepcional. En la consciencia del enfermo la contingencia real de su entorno se transforma, y ello le mueve a actuaciones que resultan catastróficas para él, pero divertidas para los testigos. Al menos en la intención del autor, los lectores habrán de identificarse con estos últimos, pues en ellos encuentran la percepción desapasionada de la realidad. La simpleza y cierta avaricia de Sancho le hacen participe en el error y víctima de sus consecuencias.

En la mente, muy aguda por otra parte, del autor del Quijote apócrifo no caben la perplejidad ni la visión dinámica que tuvo Cervantes de una personalidad que se forma y evoluciona en el devenir de la existencia. No hallaremos rastro en su libro de esa locura lúcida de don Quijote y discreta simpleza de Sancho Panza, definidas por Francisco Márquez Villanueva como locura paradójica ${ }^{7}$, que son atractivo principal de la obra maestra cervantina para el lector de hoy. Pero si fue involuntaria la opacidad del hidalgo y del escudero apócrifos, no ocurre lo mismo con las consecuencias de sus actos. Como Gilman demostró, al margen de las tensiones del mundillo literario que se transparentan en la acusación de que Cervantes ofendió a Lope de Vega y al propio autor encubierto, éste se siente defensor de un orden social y una doctrina que aparecen como problemáticas en el libro de Cervantes. Avellaneda debió percibir esta ambigüedad y comprender que cuando don Quijote funde, por ejemplo, libertad y virtud en su utópica proyección de la Edad de Oro hacia el futuro, el autor está expresando a través del personaje sus aspiraciones más profundas. A darle una réplica, tanto como a sacar partido de la invención cervantina, se encamina el apócrifo, de cuya lectura puede deducir el público cuál sería el resultado de la evasión de la norma que provoca la locura del hidalgo. En este libro traerá como consecuencia, no sólo palos y burlas sino también la pérdida de la honra y la muerte civil que suponía el ingreso en un manicomio.

$\mathrm{La}$ obra de Avellaneda, con sus disparatadas y a veces indecentes escenas de confusión y violencia, está concebida bajo la estética de lo cómico. Gilman la compara a las comedias de Molière, en cuanto los principales personajes,

- Stephen Gilman, Cervantes y Avellaneda, estudio de una imitación, trad. de Margit Frenk, México, Colegio de México, 1951.

7 "La locura emblemática en la segunda parte del Quijote", en Cervantes and the Renaissance, ed. Michael D. McGaha, Newark Del., Juan de la Cuesta, 1980, págs. 81112. Véase también Juan Bautista Avalle-Arce, "La locura de vivir", en Don Quijote como forma de vida, Madrid, Castalia, 1976, págs. 98-143. 
que se mueven en el plano ilógico, encarnan cada uno un defecto que la sociedad condena ${ }^{8}$. En un trabajo donde hace hincapié en la comicidad del Quijote auténtico, Peter E. Russell ${ }^{9}$, comentó que la hilaridad de los testigos que ven actuar a los ridículos protagonistas se manifiesta de modo más constante en la continuación apócrifa que en la cervantina. Extremando esta postura, se ha podido afirmar que los protagonistas que se espera encontrar después de leer la primera parte tienen más en común con los de Avellaneda que con los de la Segunda Parte de Cervantes ${ }^{10}$. Si esto es así, viene a confirmar la opinión expresada por Menéndez Pidal de que Cervantes, al leer a Avellaneda, "vio más claros que nunca los peligros de trivialidad y grosería que la fábula entrañaba y se esforzó más en eliminarlos al redactar la segunda parte del Quijote" ". Quizás por ello supo crear, no sólo personajes de ficción sino también personajes novelescos, los primeros de la novela moderna, que asume, copiando a la vida, la compleja unicidad de cada ser humano.

Inútilmente se buscaría entre los pasajes divertidos del apócrifo los que pudieran duplicar en su efecto sobre el lector la gama de risas cervantinas, que ha analizado Alan S. Trueblood: la risa amarga, la risa disimulada, la risa de alivio y la cada vez más frecuente risa de simpatía ${ }^{12}$. Ello depende en parte de que Avellaneda concibe el libro, según se ha dicho, como obra cómica en el sentido clásico; debe, pues, producir hilaridad a costa de los defectos de personajes que sean representativos de un nivel humano y social bajo o medio. Podria aplicarse al proceso de lectura la observación que hizo el Pinciano respecto a la experiencia del público que asiste a la representación de una pura comedia: "Aunque en los actores aya turbaciones y quexas, no passan, como he dicho, en los oyentes, sino que de la perturbación del actor se fina el oyente de risa" ${ }^{13}$. Esta norma, que excluye la identifi-

8 Gilman cita el juicio de Rousseau a propósito de la comicidad en Molière, pero advierte que, por tratarse de una novela, en el Quijote apócrifo los valores están también presentados de forma positiva. $O p$. cit., págs. 128-129. Sobre la dualidad de planos lógico e ilógico, cf. pág. 143.

- "Don Quixote as a funny book", MLR, XLIV, 1969, págs. 312-326.

10 Howard Mancing. The Chivalric World of Don Quijote, Style, Structure and Narrative Technique, Columbia, Miss., Univ of Missouri Press, 1982, págs. 188-189.

11 "Un aspecto en la elaboración del Quijote" (discurso de $1920 ; 2{ }^{\mathrm{a}}$ ed. aumentada, 1924). En De Cervantes y Lope de Vega, 5. ${ }^{\mathrm{a}}$ ed., Buenos Aires, 1946 (Austral, 120), págs. 41-42.

${ }_{12}$ "La risa en el Quijote y la risa en don Quijote", Cervantes [Cervantes Society of America], IV, 1984, págs. 3-23.

1s Antes había dicho: "Y la diferencia que ay de los temores trágicos a los cómicos es que aquéstos se quedan en los mismos actores y representantes solos, y aquéllos passan de los representantes en los oyentes." Alonso López Pinciano, Philosophia antiqua poética (1596), ed. de Alfredo Carballo Picazo, Madrid, C. S. I. C., 1953, págs. 24 y 26 . 
cación del espectador o lector con la figura cómica, controla la lectura que hace Avellaneda de la primera parte del Quijote, tanto como su creación propia.

En el apócrifo, don Álvaro Tarfe ilustra perfectamente la categoria de personaje que, con referencia a épocas posteriores, se ha definido en los términos siguientes: "the character who while more fully delineated and individualized than any background character, exists in the novel primarily to serve some function. Unlike the protagonist he is ultimately a means to an end rather than an end in himself" ${ }^{14}$. En el caso de que tratamos, esta función consiste en ofrecer un incentivo a la actuación anormal del protagonista, creando deliberadamente una situación ficticia que confirme sus fantasias y le mueva a repetir el tipo de comportamiento que en los episodios iniciales del Quijote de 1605 obedecía a la transformación en materia de aventura de alguna circunstancia propia de la vida cotidiana. Todos reconocemos la semejanza de las iniciativas que tiene en la obra de Avellaneda don Alvaro Tarfe - calificado recientemente por Giovanna Calabrò ${ }^{15}$ de "metteur en scène"- con las que se atribuyen en la Segunda parte cervantina a los duques y su pequeña corte. También son similares las motivaciones de las burlas, pues en ambos libros los personajes organizadores de las fiestas y mascaradas buscan su propia diversión o la de sus señores, aunque no falte al fin una cierta benevolencia hacia el enfermo que se ha utilizado como bufón.

Este aspecto funcional de la figura que comentamos se relaciona con uno de los dilemas que presenta la comparación de las obras en que aparece. Como Cervantes publicó su Segunda parte al año siguiente de aparecer la de Avellaneda, se ha planteado la posibilidad de que en este importante aspecto estructural el imitador fuese el imitado, aunque no haya punto de comparación entre la diversidad y gracia de las mascaradas que tienen lugar en la frívola corte ducal y las fiestas descritas en el Quijote apócrifo, cuyo mayor mérito consiste en retratar con fidelidad algunas costumbres áulicas del momento ${ }^{16}$. Dada la alta capacidad creadora de Cervantes, parte de la crítica ha considerado improbable que se sirviera de un esquema aprendido en un libro, que le ofendió hasta el punto de que, utilizando la peripecia como signo,

14 W. J. Harvey, Character in the Novel, Ithaca, Cornell University Press, 1965, pág. 58.

15 "Cervantes, Avellaneda y Don Quijote", ACerv, XXV-XXVI, 1987-1988, páginas $87-100$. La autora de este artículo ha prologado una reimpresión de la traducción de Avellaneda al italiano, por Gilberto Beccari, Il secondo Chisciote, Nápoles, Guida, 1983 , libro al que no he tenido acceso.

16 Cf. Lucien Clare, La Quintaine, la course de baque et le jeu des têtes, Paris, CNRS, 1983, pág. 135 . 
cambió el itinerario de sus personajes para que no se confundieran con los espúreos.

Sobre esta base y teniendo en cuenta otras aproximaciones muy concretas, James Fitzmaurice Kelly ${ }^{17}$ planteó ya en 1892 la posibilidad de que Avellaneda hubiese tenido noticia de la composición de la Segunda parte años antes de su publicación, a través de los correveydiles del mundillo de las letras, puesto que se sabe que Cervantes leía algunas veces a sus amigos fragmentos de su obra. En 1919 a Menéndez Pidal le parecía improbable esta hipótesis ${ }^{18}$, y en 1972 mantenia la misma reserva Martin de Riquer. En su opinión, cuando Cervantes conoció la obra de Avellaneda, introdujo adiciones en el texto que ya había escrito, incorporando y superando ciertos rasgos de la espúrea continuación ${ }^{19}$. En cambio Gilman ${ }^{20}$ consideraba improbable que el creador del Quijote auténtico se hubiese dejado guiar por el imitador y rescató la hipótesis de Fitzmaurice Kelly. Hacia 1960 Alberto Sánchez ${ }^{21}$ admitía la posibilidad de que Avellaneda conociese de oídas la Segunda parte cervantina cuando escribió su obra. A la misma opinión se inclina, con grandes reservas, diez años después Fernando García Salinero en su Introducción al apócrifo ${ }^{2}$. Louis Andrés Murillo ${ }^{23}$, que se plantea la cronología de la redacción del Quijote, cree que la tercera y última fase de la escritura se inicia con el capítulo 59, compuesto bajo el efecto de ver impreso el libro de Avellaneda. Esta amarga experiencia mueve al autor a apropiarse de la obra espúrea, englobándola entre las realidades de la fábula, con lo cual queda descalificada. En lo que si coincide la crítica es en valorar ese estímulo, derivado de la lectura del apócrifo, que indujo a Cervantes a individualizar al máximo sus protagonistas. Podemos, por lo tanto, suponer que también el tratamiento dado a las características humanas y sociales de don Alvaro Tarfe forma parte de la réplica cervantina.

Advierte Philippe Hamon, al definir los "personnages-référentiels", que estos personajes históricos, mitológicos o sociales remiten todos ellos a un sentido pleno y fijo, inmovilizado por una cultura. Dado que se les asigna

17 The Life of Cervantes, London, 1892, pág. 142. Citado por Gilman, pág. 174.

18 Estudio citado supera, nota 11.

19 Edición citada supra en nota 3, vol. I, págs. xxxv-xxxix. Básicamente sustenta la misma opinión en la Introducción a Cervantes, Obras completas I: "Don Quijote de la Mancha" seguido del "Quijote" de Avellaneda, Barcelona, Planeta, 1. a ed. 1962, 2. ${ }^{2}$ ed. 1967 y 3. ${ }^{2}$ ed. 1968.

20 Apéndice: "Avellaneda y la auténtica Segunda Parte", op. cit., págs. 167-176.

21 El "Quijote" de Avellaneda, Curso de Conferencias para Preuniversitarios (19591960), Madrid, s. a.

22 Alonso Fernández de Avellaneda, El ingenioso hidalgo don Quijote de la Mancha, Madrid, Castalia, 1972, pág. 23.

2s The Golden Dial: Temporal Configuration in 'Don Quijote', Oxford, Dolphin, 1975, págs. 108-109, 116-117 y 153-163. 
una representatividad, en relación con unos programas y unos empleos estereotipados, la plena aprehensión por parte del lector de lo que significan depende del grado en que participa de esta cultura ${ }^{24}$. Para entender las referencias implícitas en el personaje que comentamos, conviene recordar el efecto que produce la aparición en la plaza del pueblo de Argamasilla de "quatro hombres principales a cavallo, con sus criados y pajes y doze lacayos que trahían doze cavallos de diestro ricamente enjaezados" (Cap. 1, I, 29). Los vecinos, que se han reunido a charlar después de rezar las Vísperas, se quedan suspensos. El cura comenta: "Por mi santiguada, señor Quijada, que si esta gente viniera por aquí oy haze seys meses, que a v. m. le pareciera una de las más estrañas y peligrosas aventuras que en sus libros de cavallerías avía jamás oydo ni visto" (ibid.). Efectivamente, aquélla no era manera habitual de viajar. Las novelas cortas del siglo xvII, empezando por las Ejemplares de Cervantes, nos muestran muchos hidalgos itinerantes que van casi siempre acompañados de uno o dos $\operatorname{criados}^{25}$. El grupo que llega a Argamasilla correspondería al séquito de un noble de alcurnia o de un dignatario. Cuando la expulsión de los moriscos era todavía más actualidad que recuerdo, debia resultar chocante que los miembros de la lujosa comitiva se identificasen como caballeros particulares de Granada. Su presumible abolengo no tarda en confirmarse. Al mismo tiempo Avellaneda da una explicación verosímil de la vistosa cabalgata, ya que esos jinetes van a participar en unas justas que se celebran todos los años en Zaragoza por San Jorge. Efectivamente, parecen componer una cuadrilla, comparable a las de Abencerrajes o Zegries que se pintan en el libro de Pérez de Hita - con el que sin duda estaba familiarizado el autor- ${ }^{26}$, o a las que sacan en las fiestas ecuestres, desde el rey o el príncipe hasta la corporación de caballeros de la ciudad donde tienen lugar los juegos. El lujo de estos granadinos pudiera ser una manera de recordar la riqueza tantas veces reprochada a los moriscos. Ante su cortesía un poco arcaica, no falta un alcalde rústico que los compara fa-

\footnotetext{
24 "Pour un statut sémiologique du personnage", en volumen colectivo Poétique du récit, Paris, Seuil, 1977, págs. 115-180. (Cita en pág. 122.)

25 Aunque se refiera al reinado de Carlos II, podemos recordar que cuando Madame d'Aulnoy visita la corte española, comenta la pragmática que prohíbe a todos los españoles, salvo los que lleven embajadas, a salir acompañados por más de dos lacayos, que pueden portar espada, y de un palafrenero, que no la lleva. Afirma que esta disposición afecta incluso a quien en su casa tiene a su servicio 400 ó 500 personas. José María Díez Borque, La sociedad española y los viajeros del siglo XVII, Madrid, Taurus, 1975, pág. 200.

28 Guerras civiles de Granada, ed. de Paula Blanchard-Demouge, Madrid, Centro de Estudios Históricos, 1913-1915, 2 vols. [Vol. I: Historia de los vandos de los Zegries y Abencerrages] (1595). Reproduce el texto de esta edición Shasta M. Bryant, Guerras civiles de Granada. I parte, Newark, Del., Juan de la Cuesta, 1982. Sobre los puntos de contacto entre Pérez de Hita y Avellaneda, véase supra y notas 30 y 40.
} 
vorablemente con "las capitanias [compañias] de otros mayores fanfarrones que ellos", a quienes muchas veces se ven obligados a dar hospedaje (cap. 1, I, 31).

El cura distribuye a los huéspedes, y envía al principal a casa de don Quijote. Alli el granadino se maravilla de lo que oye, pero a su vez cuando él se identifica como don Alvaro Tarfe, descendiente del antiguo linaje de los moros Tarfes, y cuando describe a su dama, que es de corta estatura, con exagerado preciosismo y ostentosa erudición sospecho que también queda inserto en la órbita de lo estrambótico. El orgullo nobiliario que se apoya en una referencia elíptica a las Guerras civiles de Granada de Ginés Pérez de Hita y la conversión de las principales familias moras, lleva su punta de ironia. Al fin y al cabo, si la acción fuese estrictamente coetánea, los viajeros que acuden a las justas de Zaragoza "para ganar en ellas alguna honra" (cap. 1, I, 31), como ellos mismos dicen, podrían haber sido expulsados de España, o verse forzados a disimular la ascendencia de que hacen alarde.

Para confirmarlo podemos recurrir a un testimonio literario que parece reflejar un caso real. En la novela de Lope de Vega "La desdicha por la honra", que aparecerá cuatro años después que el Quijote apócrifo, nadie sospecha en la corte del Virrey de Nápoles que un caballero que le sirve, educado en Toledo, sea un Abencerraje, hasta que él mismo lo descubre en una carta de despedida a su señor, donde le comunica que sus padres, aunque se creian nobles, han sido expulsados de España como moriscos. En este caso, el escritor si debió tener presente un modelo vivo de renegado, que se movia entre la órbita cristiana y la otomana, sin pertenecer de lleno a ninguna de ellas ${ }^{27}$. También a través de un episodio con cierto sesgo autobiográfico de la comedia La villana de Getafe, Lope muestra como un falso rumor de que galán y gracioso son moriscos está a punto de dar al traste con las aspiraciones matrimoniales del primero ${ }^{28}$.

Volviendo a don Álvaro Tarfe, el indicio de burla más claro consiste en el apellido del personaje ${ }^{29}$, puesto que, entre tantos gentilicios poéticamente

27 Cf. Marcel Bataillon, “\&La desdicha por la honra»: génesis y sentido de una novela de Lope", NRFH, I, 1947, págs. 13-42. (Incluido en Bataillon, Varia lección de clásicos españoles Madrid, Gredos, 1964, págs. 373-418.) Hoy día contamos con un excelente estudio de numerosos casos reales que compiten en dramatismo con cuantos destinos escindidos pueden espigarse en la literatura: Bartolomé y Lucile Bennassar, Les Chrétiens 'd'Allah. L'histoire extraordinaire des renégats. $X V I^{\bullet}-X V I I^{\bullet}$ siècles, Paris, Perrin, 1989.

28 Cf. el estudio de Bataillon citado en la nota anterior; Márquez Villanueva, "Lope, infamado de morisco: \&La villana de Getafe»", en Lope: Vida y valores, Puerto Rico, EDUPR, 1988, págs. 293-331, y el Estudio Preliminar de José María Díez-Borque a su edición de Lope de Vega, La villana de Getafe, Madrid, Orígenes, 1990, págs. 11-12 y 44-47.

29 "La nomination du personnage n'est rien d'autre, au vrai, qu'un acte d'onomato- 
prestigiosos como ofrecian la novela y el romancero morisco el autor fue a elegir el nombre que remite a la conocida leyenda de "el triunfo del Ave Maria". Se trata de una variante del motivo del reto lanzado ante una fortaleza por un campeón contrario. En este caso un moro valiente pero descortés, llamado Tarfe en la mayoria de las versiones, ofende la sensibilidad religiosa de los Reyes Católicos y sus caballeros cuando se presenta ante los muros de Santa Fe, arrastrando de la cola del caballo un cartel con la divisa "Ave Maria", y profiere un arrogante desafio. En la múltiple difusión de la leyenda, a través de pliegos de cordel y comedias de moros y cristianos -incluidas Los hechos de Garcilaso de la Vega y Moro Tarfe y El cerco de Santa Fe de Lope de Vega-, se opone a la estampa del reto la del triunfo final del campeón cristiano, cuando cabalga con la devota divisa al pecho y la cabeza del moro retador clavada en la punta de la lanza ${ }^{30}$.

Avellaneda introduce una clara alusión a esta leyenda cuando don Quijote, utilizando las armas que su huésped dejó en su casa, toma parte en el juego de sortija que éste organiza en Zaragoza y corre con él tres lanzas. La divisa de don Alvaro ridiculiza sin paliativos a su compañero: "Aqui traygo al que ha de ser, / según son sus disparates, / príncipe de los orates," (capítulo 11, I, 207). Se nos dice que "con la letra rieron todos quantos sabían las cosas de don Quixote", pero ¿no se reirían también de don Alvaro los espectadores, al percatarse de que la divisa del hidalgo loco hace una alusión clarísima al Tarfe fanfarrón del romancero, aunque no se le nombra? Lleva el ridículo caballero andante - como tal le han caracterizado por sus armasel cartel del Ave María en la punta de la lanza, y además por cuenta propia ha añadido a los motes y pinturas de su adarga la siguiente letra: "Soy muy más que Garcilaso, / pues quité de un turco cruel / el Ave que le honra a él." (Cap. 11, I, 208-209.) Es difícil que esto no lleve intención de ridiculizar al granadino. Por otro lado, en un episodio posterior don Quijote irrumpe en una disparatada paráfrasis del famoso reto: "Salga Galindo, salga Gar-

mancie." La onomancia pretendía adivinar, a partir del nombre, calidades esenciales. Maurice Molho, “'Le nom' - le personnage”, en Le Personnage en question. Actes du IV Colloque du S. F. L., Toulouse, Université de Toulouse-Le Mirail, 1984, págs. 85-92.

30 En una aproximación del tema al combate de David y Goliat, propiciada por una leyenda genealógica que hizo fortuna, se caracteriza como caballero novel, casi niño, al campeón cristiano bajo el nombre de Garcilaso de la Vega. Diversos romances, comedias y fiestas de moros y cristianos ofrecen variantes del tema, como indiqué en " $E l$ cerco de Santa $\mathrm{Fe}$ de Lope de Vega, ejemplo de comedia épica”, Homenaje a William L. Fichter, Madrid, Castalia, 1971, págs. 115-125, y "La fiesta de moros y cristianos y la cuestión morisca en la España de los Austrias", en Actas de las Jornadas sobre Teatro Popular en España, coordinadas por J. Alvarez Barrientos y A. Cea Gutiérrez, Madrid, C. S. I. C., 1987, págs. $65-84$, notas 3 y 17.

Relaciona el nombre del personaje de Avellaneda con el protagonista del famoso reto y otros Tarfes del romancero morisco, Manuel Muñoz Barberán, La máscara de Tordesillas, Barcelona, Eds. Marte, 1974, págs. 149 et passim. Cf. supra, nota 40. 
cilaso, salga el buen maestre y Machuca, salga Rodrigo de Narváez; muera Muça, Zegri, Gomel, Almoradín, Zayde y la demás gente galguna, mejor para caçar liebres que para andar en las lides, Fernando soy de Aragón [...]" (cap. 24, II, 221-222).

No falta el nombre de Tarfe entre los moros estilizados del romancero nuevo, pero creo que la tradición que he reseñado influye en que aparezca repetidamente en desventaja. Es el amante desdeñado y celoso en "Abrasado en viva llama, / Bravo, feroz y rebelde," o "Si tienes el corazón, / Zaide, como la arrogancia,"; es el rival amenazado en "Mira, Tarfe, que a Daraja / No me la mires ni hables,"; el murmurador en "Di, Zaida, ¿de qué me avisas? / ¿Quieres que muera y que calle?" ["miente el infame de Tarfe"]. También se le adjudica en "Mira, Zaida, que te digo / Que andas cerca de olvidarme," el papel de hombre rico, dueño de los jardines donde otros se divierten ${ }^{31}$. De todo ello creo podemos deducir que Avellaneda buscó para su hidalgo morisco un apellido incómodo, aunque algo lo compensó con el nombre de pila. Alvaro tiene resonancias aristocráticas, al tiempo que es antropónimo frecuente entre moriscos, quizás porque San Alvaro fue el célebre mártir mozárabe de la Córdoba islámica. Justamente bajo este mismo nombre presentaria Calderón en Amar después de la muerte ${ }^{32}$ a El Tuçani, morisco que, según Pérez de Hita, jugó un papel en la rebelión de 1568 y protagonizó una historia lastimosa de amor y venganza.

Tenemos una indicación de que al autor del Quijote apócrifo le interesaba destacar el apellido desfavorable del personaje que estudiamos en el hecho de que, en dos ocasiones, Sancho Panza cometa el error, que nadie le corrige, de llamarle "señor don Tarfe" (cap. 2, I, 48 y 59). No repetirá, por cierto, la equivocación cuando se vea necesitado de la intervención del caballero granadino, pues entonces suplica: " $\mathrm{Ha}$ señor don Alvaro Tarfe!" (cap. 8, I, 175). El efecto grotesco del tratamiento de "don" con un antropónimo ára-

s1 Los conocidos romances citados figuran en el Romancero general de 1600 . Pueden leerse en: Romancero general, compilado por Agustín Durán, vol. I (BAE, 10), Núms. [siguiendo el orden de la mención] 70,63, 133, 58 y 57. Tarfe también aparece en otros casos con los rasgos usuales del sujeto poético de los romances moriscos (Núms. 71-74).

32 No Alvaro, sino Fernando de Figueroa es el nombre cristiano que adoptará el personaje de Pérez de Hita al fin de su aventura, acogido a la protección de don Lope de Figueroa. Guerras civiles de Granada, vol. II [Seguna parte], pág. 339. Sobre el drama de Calderón, véanse los estudios de Ángel Valbuena Briones, "La guerra civil de Granada a través de Calderón”, en Homenaje a William L. Fichter, Madrid, Castalia, 1971, págs. 735-744; José Alcalá Zamora, "Individuo e historia en la estructura teatral de «El Tuzaní de la Alpujarra»", en Calderón. Actas del Congreso ... 1981, ed. de Luciano García Lorenzo, Madrid, C. S. I. C., 1983, vol. I, págs. 343-363; José Miguel Caso González, "Calderón y los moriscos de las Alpujarras", ibid., págs. 393-402, y Thomas E. Case, "Honor, Justice and Historical Circumstance in \&Amar después de la muerte»", Bulletin of the Comediantes, 36, núm. 1, verano 1984, págs. 55-69. 
be ${ }^{33}$, obedece a que no se utilizaba, ni en la literatura ni en la vida, como calificación del musulmán cuyo rango equivalia al del cristiano que lo usaba. En cambio, al menos en el tratamiento literario, el convertido, si es caballero, recibe invariablemente al bautizarse nombre de pila con "don". Cuando a Sancho le viene a la mente "Don Tarfe" es porque Tarfe le suena como nombre de personaje, y esto sólo se explica por la tradición del duelo del Ave Maria, que además ya hemos visto que aporta otra nota de comicidad.

También podemos replantearnos si la intención de Avellaneda sería realmente encomiar, como suele pensarse, lo que hoy nos parece frívolo y cruel en la conducta de don Álvaro Tarfe, ya que explota sistemáticamente la locura de don Quijote para su propia diversión y lucimiento como organizador de festejos. Al fin y al cabo, Cervantes mostró con poca simpatía un censor de parecidos comportamientos en el eclesiástico del Quijote ${ }^{34}$ que representa unos criterios de moralidad comparables a la posición de Avellaneda ${ }^{35}$. Desde el momento en que tenemos en cuenta el valor referencial del personaje, sospechamos que el autor incluye en su burla a quienes, aun conservando la destreza, han perdido muchos privilegios de la condición de nobles y por lo mismo se aferran a esos juegos aristocráticos, heredados de un pasado que fue para su linaje más favorable que el presente. Al fin y al cabo, al correr una lanza o alancear un toro, el caballero morisco, ante quien tantas puertas se cierran, puede sentirse identificado con el moro del pasado.

En la España de los Austrias, gran número de estas familias habían adoptado el apellido de sus padrinos. De ahi que no sepamos, por ejemplo, cuáles de los ingenios que formaban parte de las academias poéticas patrocinadas por los Granada Venegas formaban parte de la sociedad granadina neocristiana, a excepción de los propios anfitriones, quienes, como descendientes que eran de la casa real nazari, se habían incorporado a la alta nobleza castellana y no ocultaban su linaje. Si pusiéramos en relación vida y literatura, podríamos esperar encontrarnos alli aquella descendencia de los moros enamorados Ozmin y Daraja, a que alude - a mi juicio intencionadamente ${ }^{36}-$

ss La variante "Atarfe", que es antropónimo y gentilicio frecuente en el romancero morisco, está registrada con el significado "especie de tamarisco" por Leopoldo de Eguilaz y Yanguas, Glosario etimológico de las palabras españolas... de origen oriental (1886), Madrid, Atlas, 1974, pág. 305.

34 Interviene en los capítulos 31-32 de la Segunda parte; ed. cit. en nota 4, vol. II, págs. 278-284.

ss Gilman compara con el autor del apócrifo a este personaje, que le parece "el más imperdonable de los diversos Antiquijotes". Op. cit., pág. 58. Concuerda en el Prólogo Américo Castro, al afirmar que Avellaneda "adivinó los pensamientos del eclesiástico insultador de Don Quijote en casa de los Duques, y puso bien de manifiesto cuán a contrapelo de las preferencias literarias de su tiempo había escrito Cervantes.". Páginas 5-6.

36 Remito a mis comentarios en "El trasfondo social de la novela morisca del siglo xVI", DICENDA, II, 1983, págs. 43-56. 
Mateo Alemán al concluir su novelita morisca ${ }^{37}$. En las Guerras civiles de Granada de Pérez de Hita se especifican nombres de nuevos cristianos, como el de un "cavallero Abencerrage muy principal, llamado quando moro Alí Mahomad Barrax, y Christiano Don Pedro Barrax." 38.

Además, este libro, que no ofrece rasgos veristas en la psicología de los personajes ni en el desarrollo de las intrigas secundarias, se atiene estrictamente a la realidad del tiempo de composición de la obra en la descripción material de las galas moriscas ${ }^{39}$. Sin duda, esas joyas, prendas y jaeces son en su obra signos de un estado anímico, pero al mismo tiempo tales objetos, palpables y preciados, que Pérez de Hita describe en sus pormenores de manufactura y calidad con entusiasmo de entendido, tienden un puente entre el mitificado pasado musulmán de la acción novelesca y ciertas facetas de la vida real que tenian para los moriscos un significado especial. Al correr una lanza o alancear un toro, el caballero morisco, ante quien tantas puertas se cierran, puede sentirse identificado con el moro del pasado. Avellaneda lo sabía muy bien y acentuó en sus personajes de abolengo moro el atildamiento y lujo en el vestir, asi como la importancia que conceden a las fiestas de tipo caballeresco, donde pueden lucir su destreza en juegos ecuestres. Teniendo todo esto en cuenta, se explican, a mi juicio, las coincidencias de léxico y motivos temáticos entre los dos escritores, que fueron observadas por Manuel Muñoz Barberán, quien propone que se trata de la misma persona ${ }^{40}$. A mi juicio, se opone a esta hipótesis una divergencia sustancial en el talante de ambos, ya que en las Guerras civiles de Granada no se halla rastro de vena satírica y en cambio sí se manifiesta un notable don para dar vida a las escenas de gran espectáculo, rasgo de que carece el autor del apócrifo, quien fue criticado precisamente en este aspecto por Cervantes, cuando califica "la

\footnotetext{
37 "[...] tuvieron ilustre generación" (Alemán Vida de Guzmán de Alfarache (1599), en Novela picaresca española, I, ed. de Francisco Rico, Barcelona, Clásicos Planeta, 1967, pág. 242).

s8 Pérez de Hita, vol. I, pág. 209. Cf. Carrasco Urgoiti, "Ginés Pérez de Hita frente al problema morisco", Actas del IV Congreso de la Asociación Internacional de Hispanistas ... 1971, Salamanca, Universidad, 1982, vol. I, págs. 269-281.

so Juan Martínez Ruiz, "La indumentaria de los moriscos, según Pérez de Hita y los documentos de la Alhambra", Cuadernos de la Alhambra, núm, 3, 1967, págs. 55-124.

40 En el libro citado supra, nota 30, asi como en Sobre el autor del "Quijote" apócrifo, Murcia, Nogués, 1989, y "Posibles alusiones a la persona y la obra de Ginés Pérez de Hita en los libros de Cervantes", en M. Criado de Val, ed., Cervantes: Su obra $y$ su mundo, Madrid, C. S. I. C., 1981, págs. 865-877. Expone el punto de vista contrario Eulalia Hernández Sánchez, Contribución al estudio de la lengua del siglo XVI: Ginés Pérez de Hita y Alonso Fernández de Avellaneda [resumen de tesis doctoral], Murcia, Universidad, 1984. Cf. también su comunicación "Pérez de Hita y Avellaneda. Algunos aspectos léxicos de la maurofilia", en Cervantes: Su obra y su mundo, páginas $857-864$.
} 
sortija" en que participó el falso don Quijote de "falta de invención, pobre de letras, pobrisima de libreas, aunque rica de simplicidades ${ }^{4}$.".

En la Segunda parte de las Guerras civiles de Granada, terminada según su autor en 1597 aunque no se dio a la estampa hasta 1619, Pérez de Hita parece recalcar a través de la onomástica la cultura mixta del sector burgués morisco ${ }^{42}$. Si durante la rebelión de la Alpujarra, los dirigentes usaron sus nombres árabes, esta dualidad no sólo se produce como yuxtaposición de dos periodos en la vida de una persona. Cuando el escritor menciona a "don Fernando Muley Abenhumeya" y recalca "(que ansi se llamava)" ${ }^{43}$ resulta evidente que estas cuatro palabras unidas, que componen una singular etiqueta, ejercian verdadera fascinación sobre el artesano que sirvió en la guerra de la Alpujarra, pues sentía como suya la cultura mixta de la España mudéjar y veneraba el pasado medieval en su doble vertiente ${ }^{4}$. El caso de Avellaneda es bien distinto y requiere una reflexión.

La crítica suele ver en don Alvaro Tarfe el representante de un sector social prestigiado. Como se ha indicado, Stephen Gilman interpretaba el Quijote apócrifo como obra cómica, pero pensaba que al pertenecer este libro al género novelístico, se manifestaban en él los valores de la sociedad en que se produjo, tanto a través de ejemplos negativos como positivos. Por ello Avellaneda mostró cómicamente el reverso de esos valores en los personajes principales, que son don Quijote, Sancho y Bárbara, mientras que según este critico don Alvaro Tarfe y otros caballeros ofrecen un modelo de actitudes encomiables, entre las que destacan el "buen gusto" y la "desenvoltura", que explícitamente los caracteriza ${ }^{45}$. Esto no me parece concluyente, dado que -aunque no sea acepción registrada en los diccionarios- un autor como Vicente Espinel, que escribe casi por las mismas fechas que Avellaneda, aplica más de una vez la expresión "hombre —o caballero- de buen gusto" al que es alegre y amigo de bromas, lo cual no lo califica moralmente en ningún

41 Cervantes, Quijote, II, cap. 59, pág. 489.

42 En estudios monográficos con información sobre la antroponimia granadina, se comprueba que el nombre oficial de muchos moriscos constaba, como el del personaje de Avellaneda, de un nombre de pila y de un apellido que revelaba su origen. Remito a Juan Martínez Ruiz, Inventarios de bienes moriscos del reino de Granada (siglo XVI), Madrid, C. S. I. C., 1972, "Onomástica" : págs. 26-27, e Indice, págs. 309-325. Esperamos la comunicación en prensa de este excepcional investigador de la Granada morisca, a quien por desdicha hemos perdido recientemente, "Antropónimos y oficios de los moriscos granadinos", IV Simposio Internacional de Estudios Moriscos (Túnez, 1989).

is Guerras civiles de Granada, vol. II, pág. 11.

4 Cf. Albert Mas, Les Turcs dans la littérature espagnole du Siècle d'Or, Paris, Centre de Recherches Hispaniques, 1967, vol. I, págs. 266-277; Carrasco Urgoiti, "Perfil del pueblo morisco según Pérez de Hita", RDTP, XXXVI, 1981, págs. 53-84, y Manuel Muñoz Barberán y Juan Guirao García, De la vida murciana de Ginés Pérez de Hita, Murcia, Academia Alfonso el Sabio, 1987.

45 Gilman, $o p$. cit., págs. 126-133 y 150-151. 
sentido ${ }^{40}$. Creo que el propio Avellaneda, aunque emplee mayoritariamente "buen gusto" dándole el sentido actual, ofrece un par de ejemplos del matiz comentado. En una ocasión, un personaje exclama, refiriéndose a uno de los lances grotescos vividos y comentados por el hidalgo loco y su escudero: "Que me maten si algunos cavalleros de buen gusto no han hecho alguna invención de gigante para reyr con don Quixote." (cap. 14, II, 40). En otro pasaje, el calificativo "dama de buen gusto" (cap. 32, III, 140) se aplica a la esposa del personaje de la corte a quien visitaron don Alvaro y don Carlos para contarles lo que se divertían a costa de Don Quijote y Sancho. A consecuencia de ello, el matrimonio les pidió que "se los llevassen a su casa aquella tarde para passarla buena" (ibid.), y el dignatario acabó sumándose al grupo de burladores, con el título de Gran Archipámpano de Sevilla 4 . También la "desenvoltura" es rasgo que adquiere, según el contexto, matices semánticos muy diferentes, desde el de despejo y gracia hasta el de "desvergüenza con liviandad" 48 .

Si considerásemos a don Álvaro Tarfe como personaje positivamente retratado, habriamos de atribuir a su creador una postura moderada respecto a la cuestión morisca, aún palpitante cuando escribe el libro ${ }^{49}$, lo cual no sería congruente con su tendencia a apoyar las posiciones mayoritarias y ofi-

48 Antes de contar una anécdota basada en una respuesta ingeniosa de don Gabriel Zapata, se le presenta como "gran caballero y cortesano y de excelentísimo gusto" (Relación I, descanso 1, vol. I, pág. 89). Marcos cuenta que un caballero que tenía dos hijos pequeños le preguntó si quería criárselos: "le respondí que criar niños era oficio de amas y no de escuderos; rióse y dijo: 'Buen gusto tenéis [...]'” (Rel. I, desc, 6, vol, I, pág. 144). Después de sufrir - como don Diego en El Buscón de Quevedo- las burlas de estudiantes que explotan su vanidad: "El bellaco del burlador vino a la tarde riéndose mucho, y yo más; porque no entendiese que me había corrido, dijele que quería por mi amigo a hombre de tan buen gusto" (Rel. I, desc. 9, vol. I, pág. 186). De un personaje histórico, que poco después demostrará tener sentido del humor, se dice: "Era Almirante don Diego Maldonado, caballero de bonisimo gusto, en cuya gracia yo cai [...]" (Rel. I, desc. 21, vol. I, pág. 285). También es "caballero de excelentísimo gusto" el Conde de Lemos. Estando Marcos a su servicio, un hombre bajo, que le atribuye poderes mágicos, le pide un remedio para crecer. Empieza por negárselo, pero llegan “cuatro amigos de buen gusto y no poca malicia" a proponer que le hagan una burla. "Yo me sangré en salud, refiriéndole el cuento al Conde, que le solenizó mucho con su buen gusto" (Rel. I, desc. 23, vol. I, págs. 305, 310 y 314). Remito a mi edición de Vicente Espinel, Vida del escudero Marcos de Obregón (1618), Madrid, Castalia, 1972, donde se cita (vol. I, pág. 89) un pasaje de Juan Rufo que ilustra el mismo sentido de la expresión.

47 Facilitan la consulta léxica del Quijote apócrifo las Concordancias del \&Quijote» de Avellaneda, compiladas por Enrique Ruiz Fornells, Madrid, Fundación Universitaria Española, 1984.

48 Acepción que el Diccionario de Autoridades registra con un ejemplo de Saavedra Fajardo.

4 La serie de apologías de la expulsión se prolonga hasta 1618. Cf. Márquez Villanueva, El problema morisco (Desde otras laderas), Madrid, Libertarias, 1991, pág. 104. 
ciales ${ }^{50}$. Esta reflexión puede reforzar la lectura que proponemos del don Álvaro Tarfe de Avellaneda como figura cómica, en torno a la cual se insinúan notas negativas ${ }^{51}$ que serían evidentes a los ojos del lector coetáneo, aunque a nosotros se nos escapen fácilmente, en parte porque se nos ha esfumado lo que fue la realidad social del hidalgo de origen moro. Por fortuna, la investigación sobre los moriscos se ha desarrollado de forma importante durante los últimos treinta años 52 , y hoy podemos empezar a estudiar ciertos personajes literarios que representan sectores sociales impregnados de mudejarismo. Son muy pocos, sin embargo, los que pertenecen, como don Alvaro Tar$\mathrm{fe}$, a la sociedad burguesa, quizás porque sus modelos vivientes se envolvieron en una penumbra que la investigación histórica no ha disipado aún.

Sugiero que don Álvaro Tarfe y sus amigos, granadinos o cortesanos, no representan globalmente a la sociedad, sino a una juventud ociosa y frívola que el autor del apócrifo rebaja por el solo hecho de encarnarla en quien disimula su condición de marginado recurriendo al ropaje de las fiestas y al lenguaje de la burla. En los juegos hípicos la nobleza e incluso la realeza españolas perpetuaban, efectivamente, junto a una tradición común europea, ciertas formas de ocio, como la lidia y el juego de cañas, que fueron patrimonio de los caballeros andalusís. Esto molestaba a los más acérrimos enemigos de los nuevos convertidos de moros. En el terreno poético, el género del romance morisco, tan relacionado con la moda áulica y especialmente con la fiesta ecuestre, hubo de ser tildado de herejía. "Renegaron de su ley / Los romancistas de España / Y ofrecieron a Mahoma / Las primicias de sus gracias," 53 , leemos en un romance nuevo, que no dejó de suscitar una réplica

so Observó esta contradicción Manuel Durán, "El «Quijote» de Avellaneda", en Suma cervantina, ed. por J. B. Avalle Arce y E. C. Riley, Londres, Támesis, 1973, págs. 357-376. Cf. pág. 376.

s1 Discrepa de la mayor parte de la crítica en la valoración del personaje de Avellaneda Nicolás Marín, quien advierte que la simpatía con que se le suele juzgar deriva de su amistad con don Quijote. Pero dado que en el apócrifo este último no merece la estima del lector, tampoco puede juzgarse positivamente a quien es en gran medida responsable del tristísimo espectáculo de fealdad y miseria moral que ofrecen los protagonistas. Cf. "Reconocimiento y expiación: don Juan, don Jerónimo, don Alvaro, don Quijote", Estudios sobre literatura y arte dedicados al Profesor Emilio Orosco Diaz, Granada, Universidad de Granada, 1979, vol. II, págs. 323-342. Recogido en Nicolás Marín López, Estudios literarios sobre el Siglo de Oro, ed. póstuma a cargo de A. de la Granja, Granada, Universidad, 1988.

a Véase Miguel Ángel de Bunes, Los moriscos en el pensamiento histórico, Madrid, Cátedra, 1983, cap. 3 y Bibliografía. Entre los libros aparecidos en la última década : Louis Cardaillac, ed., Les Morisques et leur temps. Table ronde internationale ... (1981), Paris, C. N. R. S., 1983; Luce López-Baralt, Huellas del Islam en la literatura española. De Juan Ruiz a Juan Goytisolo, Madrid, Hiperión, 1985; Bernard Vincent, Andalucía en la Edad Moderna: Economía y sociedad, Granada, Diputación, 1985, y Márquez Villanueva, El problema morisco. Cf. nota 61.

ss "Tanta Zaida y Adalifa, / Tanta Draguta y Daraxa," figura en la Flor Tercera 
en que se afirma: "Si es español don Rodrigo, / español el fuerte Abdala,". De modo semejante al primer romancista, sospecho que zahiere Avellaneda indirectamente a quienes imitan en sus diversiones a los enemigos de ayer, cuyos despreiados hijos adquieren asi un cierto grado de prestigio. El don Alvaro Tarfe que en el capitulo treinta y dos del Quijote apócrifo visita al rey con otros caballeros se ha presentado como descendiente de moros. No pasaría ninguna prueba de limpieza de sangre, salvo que adujera pruebas falsas. La posibilidad de que todo ello esté envuelto en un halo cómico me parece coherente con la hostilidad sin paliativos que su autor muestra ante cualquier intento de dar relevancia ética o valor emblemático al ideal caballeresco. Al fin y al cabo, los géneros moriscos representan una variante moderna de ficción caballeresca, en la cual, además, los musulmanes comparten ciertos valores con los cristianos o encarnan en solitario un paradigma de cortesania.

La expulsión de los moriscos y sus secuelas tuvieron lugar por los años en que Cervantes debía andar configurando en su mente la tercera salida y las últimas aventuras de don Quijote. Él no habia soslayado en sus escritos la presencia morisca en la España coetánea, como hicieron muchos de sus predecesores, aunque no falta ambigüedad en su tratamiento. Nos conviene recordarlo para entender su respuesta a Avellaneda en referencia a este tema. Comenzaremos por el "Coloquio de los perros", donde el personaje que representa a los nuevos convertidos apenas se desarrolla, ya que nada ocurre durante el episodio, salvo que el perro narrador pasa hambre y abandona la casa del tacaño hortelano morisco para seguir al poeta de comedias. En cambio Berganza emite opiniones muy negativas que obtienen el respaldo de su compañero Cipión. Este juicio ha sido interpretado como prueba de que, al menos por los años en que escribe el "Coloquio", Cervantes asumía una posición anti-morisca, pero la intención irónica del fragmento es más que posible ${ }^{54}$.

(1593). El romance más representativo de esta tendencia quizás sea “ $i$ Ah! mis señores poetas / Descúbranse ya esas caras,", que apareció en el tomito compilado por Sebastián Vélez de Guevara Quarta y Quinta parte de Flor de romances (1592). La réplica “¿Por qué, señores poetas, / No volvéis por vuestra fama?" se incluye en la Flor Quinta (Burgos, 1592). Estos y otros poemas anti-moriscos pasaron al Romancero general de 1600. Figuran los citados en Durán, Núms. 244-246. Sobre este tipo de romance satírico véase Robert Jammes, Etudes sur l'oeuvre poétique de Don Luis de Góngora y Argote, Bordeaux, Institut d'Etudes Ibériques et Ibéro-Américaines, 1967, págs. 461464 ; Carrasco Urgoiti, "Vituperio y parodia del romance morisco en el romancero nuevo", en Culturas Populares: [...] Diferencias, Divergencias, Conflictos. Actas del Coloquio celebrado en la Casa de Velázques ... nov.-dic. 1983, Madrid, Casa de Velázquez/ Universidad Complutense, 1986, págs. 115-138, y Márquez Villanueva, "Lope, infamado de morisco: La villana de Getafe" (citado supra, nota 28), págs. 310-319.

s4 Cf. Márquez Villanueva en "El morisco Ricote y la hispana razón de estado", Personajes y temas del 'Quijote', Madrid, Taurus, 1975, págs. 229-335. Véase también, 
En el Quijote de 1605 , un morisco jovial y agudo, instalado en Toledo, vive un mes en casa del primer autor, traduciendo los cartapacios que contienen en lengua árabe la historia de don Quijote. Es una figura captada en esbozo, con pluma neutra, y que pronto desaparece como personaje individualizado, aunque siga estando presente en el juego que se establece entre la realidad y su reflejo literario. Cuando Cervantes, ya enfermo y anciano, da cima a la Segunda parte ha tenido lugar la expulsión de los nuevos convertidos. Entonces urde la peregrina historia de la bella morisca Ana Félix, que se entrelaza con la muy ajustada a la realidad de su padre, Ricote. Sus amores con un caballero, hijo de un señor de lugar - conjeturamos que lugar de moriscos, pues el mayorazgo manejaba la lengua que éstos hablaban con tal soltura que podia pasar por uno de ellos- se encaminan a un desenlace en suspenso, como advirtió Vicente Llorens ${ }^{55}$, ya que Cervantes sacrificó el final feliz, que según la pauta literaria pedia el novelesco episodio, a favor del testimonio que formula el propio padre de la protagonista, cuando advierte la inflexibilidad con que se aplica el decreto de expulsión. También consideraba este crítico que el ambiente de fracaso requerido por el tema del regreso de don Quijote armonizaba con las connotaciones lastimosas que presta a estos capitulos la extinción de la España morisca. Pero volviendo a la vertiente bizantina de la historia, es evidente que la confusa identidad en cuanto a religión, hábitos, patria y lengua, que las circunstancias han impuesto a los jóvenes, halla un símbolo en el tópico del disfraz varonil para la mujer y femenino para el varón que asumen en la peripecia. Entre tanta antinomia emerge en el texto el sintagma "la morisca cristiana" ${ }^{56}$, que corresponde a una realidad, sin duda minoritaria pero no inventada por Cervantes. Para colmo de las paradojas, Ricote mismo justifica la expulsión. E1 esquema - morisca piadosa, morisco que aprueba el destierro- se repetirá en el Persiles, donde el punto de vista negativo viene dado por la actuación violenta del resto de los nuevos convertidos del pueblo y la presencia en otros episodios de una hechicera morisca. Como quiera que el enigma se descifre, no puede negarse que en estos ejemplares de ficción idealizadora, plasma emblemáticamente una tragedia colectiva que el autor vivió como testigo de excepción.

Nadie entendió las intenciones disimuladas del apócrifo mejor que Cer-

\footnotetext{
sobre la postura de Cervantes frente a los moriscos, L. P. Harvey, The Moriscos and Don Quijote. Discurso inaugural de la Cátedra de Español. University of London King's College, 1974, y Carrasco Urgoiti, "La cuestión morisca reflejada en la narrativa del Siglo de Oro", en Destierros aragoneses I. Judios y Moriscos, Zaragoza, Institución Fernando el Católico, 1988, págs. 229-251.

ss "Historia y ficción en el Quijote" (1963), en Literatura, Historia, Politica, Madrid, Revista de Occidente, 1967, págs. 143-165.

\$6 Cervantes, Quijote, II, cap. 63, pág. 529.
} 
vantes, quien probablemente conoció el libro de Avellaneda al redactar el capítulo 59 de la Segunda parte del Quijote, si no antes. En todo caso, a partir de ahi el disgusto del autor se manifiesta repetidamente por boca de los protagonistas, que se quejan de lo que de ellos se dice en la espúrea continuación de la historia de sus aventuras. El procedimiento cambia cuando, a punto de llegar a su aldea, tienen el significativo encuentro con don Álvaro Tarfe, personaje relevante entre los inventados por Avellaneda, quien certifica que las personas que ahora conoce - los auténticos don Quijote y Sancho Panza- no son las mismas que habia tratado anteriormente.

Por su parte, el hidalgo granadino emerge con una calidad más sobria. Todas las notas ridículas han desaparecido. Su séquito se ha reducido a proporciones normales: tres o cuatro criados. Le dan, como a don Quijote, una sala tapizada de sargas, detalle en que quizás podemos leer una alusión al gusto por las aventuras imaginarias ${ }^{7}$. Al llegar al mesón, "púsose el recién venido caballero a lo de verano.”. A este simple detalle y su exquisita cortesía se reducen, quintaesenciados, el lujo y la afición a las galas del personaje del Quijote apócrifo. También desaparecen las alusiones directas a su calidad de cristiano nuevo. Solamente le oímos decir, como si con ello Cervantes nos advirtiese que mantiene el origen de la persona ficticia: "'Yo, señor [...], voy a Granada, que es mi patria.” "“iY buena patria!', replicó don Quijote" \$. En este lacónico elogio ¿debemos ver una simple frase de cortesía o el eco nostálgico de lecturas que retrataban una sociedad caballeresca? Como tantos otros detalles de los textos cervantinos, ¿no adquieren esas tres palabras un valor evocativo a la luz del contexto, en este caso las realidades sociales y el matiz irónico que se proyectaban sobre el personaje de Avellaneda? La elegancia del leve trazo con que está caracterizado el viajero que coincide en el mesón con los auténticos don Quijote y Sancho Panza ¿no implica una corrección del abigarrado retrato, presentado por el apócrifo, del inquieto y frívolo caballero morisco? La rectificación se justifica, dentro de la dinámica de las reivindicaciones cervantinas, puesto que aumenta el crédito de quien va a tener la importante misión de certificar que no existe identidad ni semejanza profunda entre las dos parejas protagonistas. Don Alvaro Tarfe lo hace en la forma que se le pide, y manifiesta su simpatía y admiración ante las personalidades que ahora se le revelan ${ }^{50}$.

57 En el capítulo anterior (pág. 574) se ha hecho referencia a las escenas de antiguas historias amorosas representadas en las sargas que decoran la estancia de don Quijote. También parece evocarse el título Las sergas de Esplandián, que dio Garci Rodríguez de Montalvo a su continuación del Amadis.

s8 Cervantes, Quijote, II, cap. 72, pág. 576.

so Nicolás Marín recalca el hecho de que comieran juntos don Quijote y don Alvaro, como detalle que manifiesta la amistad que entre ellos surge. Estudio citado supra, nota 51 . 
También cuida Cervantes de que las palabras de su personaje hagan sentir la distancia que lo separa de la previa y ajena versión del hidalgo granadino, cuando le hace decir que, aunque Sancho "tenia fama de muy gracioso, nunca le oi decir gracia que la tuviese ${ }^{\infty}$," ya que no cabe duda de que al caballero morisco del libro de Avellaneda, le divertía enormemente la simpleza del escudero.

En suma, la Segunda parte cervantina ofrece en el personaje don Alvaro Tarfe una silueta captada en pocos trazos, donde creemos reconocer el original de una leve pero tortuosa caricatura. El proceso es paralelo al que se realiza en el caso de los personajes principales, sólo que este caso no hay que buscar el modelo en el Quijote de 1605 . Se trata de un tipo social en trance de desaparición: la persona en quien coinciden la hidalguía y la pertenencia -insoslayable según una legislación cada vez más rigurosa - a la comunidad morisca. Este segmento en situación de inferioridad de la sociedad española de principios del siglo xvir, se proyecta con rasgos anacrónicos $y$ algo ridículos a través de los personajes granadinos creados por Avellaneda: don Alvaro Tarfe y su séquito. Un matiz de la respuesta de Cervantes pudo bien ser la reivindicación del caballero de origen moro, realizada mediante una parca pero totalmente positiva caracterización y la omisión de toda referencia a un linaje que los lectores ya conocen. No hace mucho que se han despedido don Quijote y Sancho de Ana Félix, la bella morisca que será esposa del mayorazgo aragonés, asi como de su padre, Ricote, que no permanecerá en España. En este nuevo retrato del hidalgo granadino, el silencio respecto a su linaje apunta hacia otro destino que de hecho fue posible para algunos "nuevos convertidos de moros" que aún formaban parte de la sociedad española : el de la asimilación plena. Al eliminar las reticencias burlonas que dejaron su huella en la creación de Avellaneda, Cervantes acoge con plena dignidad en el entorno de sus protagonistas al hidalgo desvinculado de una problemática ascendencia, que fue una realidad social de su tiempo.

60 Cervantes, ibid., pág. 577.

${ }^{81}$ Además de los trabajos citados en las notas 52 a 55 , véanse los recientes estudios de Mercedes García Arenal, "El problema morisco: Propuestas de discusión", Al-Qantara, XIII (1992), págs. 491-503, y Mikel de Epalza, Los moriscos antes y después de la expulsión, Madrid, Mapfre, 1992. 